\title{
Chính sách bình thường mới trong việc "hồi sinh" các doanh nghiệp trong bối cảnh COVID-19
}

\author{
Phạm Hà Trang, Đỗ Thị Hương Trà, Lê Thu Trang, \\ Cao Thùy Trang, Nguyễn Thị Phương Thảo
}

Đại học Quốc gia Hà Nội

Preprint DOI: $10.31219 /$ osf.io/ru2gw

Ngày 11 Tháng Hai 2022

Dịch bệnh Covid 19 kéo dài liên tiếp cho đến nay đã được 3 năm và thực sự đã trở thành một cuộc khủng hoảng toàn cầu. Với tốc độ lây lan nhanh chóng cùng với nhiều biến chủng mới, phức tạp xuất hiện đã càn quét khốc liệt trên phạm vi toàn cầu, gây ra nhiều ảnh hưởng, thiệt hại to lớn (La, 2020; Vuong, Q.H., 2022). Năm 2020 là năm mà con người phải chứng kiến những sự việc xảy ra chưa từng có tiền lệ về mọi khía cạnh của xã hội: kinh tế, giáo dục, lao động, đời sống,...và không thể không kể đến các doanh nghiệp. Nói về câu chuyện kinh tế trong và sau đại dịch, không thể không nhắc đến sự suy thoái nặng nề nhất chưa từng có trong nhiều thập kỉ qua từ những nước đi đầu như Mỹ, Trung Quốc, Nhật Bản, Đức,...trong đó Mỹ và các nước châu Âu chính là tâm điểm chính của dịch bệnh cũng như thực trạng tăng trưởng kinh tế tồi tệ nhất trong năm 2020. Sức tàn phá khủng khiếp của Covid 19 như một cú đòn giáng chí mạng vào nền kinh tế thế giới. Đại dịch như một con dao vô hình đẩy nền kinh tế vốn đang trong quá trình phục hồi vào cuộc khủng hoảng tồi tệ nhất kể từ sau Chiến tranh thế giới thứ hai, kéo theo hàng ngàn hệ lụy. Kinh tế Thế giới bỗng chốc bốc hơi hàng ngàn tỷ USD cùng những thành quả được xây dựng bao năm bỗng chốc tiêu tan. Theo số liệu số liệu của tổ chức dịch vụ pháp lý Epiq, 3.427 doanh nghiệp ở Mỹ đã nộp đơn xin bảo hộ phá sản vào nửa đầu năm 2020.Còn tại Việt Nam, theo số liệu cuối năm 2020 từ Tổng cục Thống kê, năm 2020 có tổng cộng 101,7 nghìn doanh nghiệp tạm ngừng kinh doanh có thời hạn, ngừng hoạt động chờ làm thủ tục giải thể và hoàn tất thủ tục giải thể, tăng 13,9\% so với năm trước. Đại dịch COVID-19 đã và đang để lại những hậu quả nặng nề trong tất cả các lĩnh vực nói chung và cho doanh nghiệp tại Việt Nam nói riêng. Những chính sách cũ hỗ trợ doanh nghiệp không còn đảm bảo tính hiệu quả trong tình hình mới. Do vậy, sự ra đời của những chính sách mới phù hợp với bối cảnh vừa cần phát triển kinh tế, vừa đảm bảo công tác phòng chống dịch là rất cấp thiết. Vì thế, chính sách "bình thường mới” đã được ban hành như một giải pháp kịp thời hỗ trợ và cứu vớt doanh nghiệp vượt qua khủng hoảng thời kì đại dịch. Để hiểu rõ hơn về đặc điểm cũng như hiệu quả mà chính sách này đem lại, ở phần 2 sẽ đi sâu vào nghiên cứu, từ đó đưa ra những nhận định nhằm cải thiện tính hiệu quả, góp phần xây dựng lại nền kinh tế, khôi phục lại đà sản xuất của doanh nghiệp. Nội dung sau đây sẽ trả lời những câu hỏi đã đặt ra ở phần trước. 
Trạng thái "bình thường mới” là một thuật ngữ được sử dụng trong lĩnh vực kinh tế để đề cập tới tình hình kinh tế sau khủng hoảng tài chính toàn cầu 2007-2008 và sự hồi phục sau suy thoái do đại dịch COVID-19. Thuật ngữ này lần đầu tiên được đưa ra bởi ông Mohamed El-Erian - Tổng giám đốc công ty quản lý quỹ Thái Bình Dương (Mỹ) tại Hội nghị WEF. Theo đó, trạng thái này có thể hiểu là thế giới sẽ không trở về trạng thái ổn định "bình thường" như trước khủng hoảng kinh tế. Trong lĩnh vực tài chính sẽ có sự can thiệp nhiều hơn của chính phủ, được quản lý giám sát nghiêm ngặt hơn, nguồn vốn yêu cầu cao hơn, hệ thống ngân hàng hiệu quả hơn (Phúc Minh, 2010).

Theo Đỗ Văn Quân, “Trạng thái bình thường mới” COVID-19 là trạng thái mà tại đó đất nước vừa tập trung chống dịch, vừa khôi phục và phát triển lại nền kinh tế như lúc ban đầu (Đỗ Văn Quân, 2021). Có 4 điểm đặc trưng để nhận diện “trạng thái bình thường mới”, đó là:

(1) Khi làm bất kỳ việc gì, phải vừa đảm bảo tính hiệu quả vừa đảm bảo mục tiêu; (2) Dịch bệnh là vấn đề diê̂n ra trên quy mô toàn cầu, tình huống bất thường không ai đoán trước được, tác động đến mọi giai tầng xã hội, không phụ thuộc vào trình độ phát triển hay thể chế chính trị;

(3) Tác động của dịch bệnh đòi hỏi mỗi con người, tổ chức và toàn bộ hệ thống xã hội phải năng động và có khả năng chống chịu và thích ứng với bối cảnh mới;

(4) Đặt ra nhiều vấn đề phải định hình lại, phải đối mặt với nhiều rủi ro xã hội: dịch bệnh, thiên tai, biến đổi khí hậu... (Đỗ Văn Quân, 2021)

Theo nghiên cứu của Đại học kinh tế quốc dân, phản ứng chính sách của một số quốc gia được thể hiện như sau:

Bảng 1: Phản ứng chính sách của một số quốc gia

\begin{tabular}{|c|c|c|c|}
\hline STT & Quốc gia & Chính sách tài khóa & Chính sách tiền tệ \\
\hline 1 & Trung Quốc & $\begin{array}{l}\text { Gói kích thích tài khóa khoảng } \\
1.3 \text { nghìn tỉ RMB được thông } \\
\text { qua, bao gồm những giải pháp } \\
\text { chính: } \\
\text { + Tăng chỉ tiêu cho công tác } \\
\text { chống và kiểm soát dịch; } \\
\text { + Sản xuất trang thiết bị y tế; } \\
\text { + Đẩy nhanh việc giải ngân bảo } \\
\text { hiểm thất nghiệp } \\
\text { + Giảm thuế và miễn đóng bảo } \\
\text { hiểm thất nghiệp } \\
\text { + Giảm thuế và miễn đóng bảo } \\
\text { hiểm xã hội }\end{array}$ & $\begin{array}{l}\text { + Cắt giảm } 1 \% \text { tỷ lệ dự trữ bắt } \\
\text { buộc } \\
\text { + Gói tái cấp vốn } 800 \text { tỉ RMB } \\
\text { để các ngân hàng cho các tập } \\
\text { đoàn lớn vay } \\
\text { + Yêu cầu các tổ chức tài chính } \\
\text { gia hạn đối với các khoản vay } \\
\text { dành cho doanh nghiệp vừa và } \\
\text { nhỏ }\end{array}$ \\
\hline 2 & Hàn Quốc & $\begin{array}{l}\text { + } 9.4 \text { tỷ USD ngân sách bổ sung } \\
\text { để chống dịch } \\
\text { + Gói hỗ trợ } 38 \text { tỷ USD cho } \\
\text { doanh nghiệp nhỏ }\end{array}$ & $\begin{array}{l}\text { Giảm lãi suất liên ngân hàng } \\
\text { xuống } 0.25 \%\end{array}$ \\
\hline
\end{tabular}




\begin{tabular}{|c|c|c|c|}
\hline 3 & Nhật Nhật & $\begin{array}{l}\text { + Dành } 1.8 \% \text { - } 2.7 \% \text { GDP ngân } \\
\text { sách bổ sung để hỗ trợ người } \\
\text { lao động, cho vay doanh nghiệp } \\
\text { nhỏ, và hỗ trợ tiền mặt cho } \\
\text { người dân. }\end{array}$ & $\begin{array}{l}\text { + Giảm lãi suất cho vay đối với } \\
\text { các tập đoàn chịu ảnh hưởng từ } \\
\text { dịch bệnh. } \\
\text { + } 700 \text { tỷ JPY chương trình mua } \\
\text { trái phiếu }\end{array}$ \\
\hline 4 & Mỹ & $\begin{array}{l}\text { + Dành } 2.2 \text { nghìn tỷ USD để } \\
\text { kích thích kinh tế } \\
\text { + } 105 \text { tỷ USD để đẩy mạnh } \\
\text { công tác chống dịch, hồ trợ } \\
\text { người dân khám và điều trị bệnh } \\
\text { do COVID-19 } \\
\text { + Mở khóa quỹ quốc gia } 50 \text { tỷ } \\
\text { để sử dụng ứng phó với thảm } \\
\text { họa quốc gia } \\
\text { + } 8.3 \text { tỷ USD chi cho y tế }\end{array}$ & $\begin{array}{l}\text { + Giảm lãi suất xuống còn } 0 \%- \\
0.25 \% \\
\text { + Gói } 700 \text { tỷ USD mua tài sản } \\
\text { ( } 500 \text { tỷ mua trái phiếu, } 200 \text { tỷ } \\
\text { mua chứng khoán được đảm } \\
\text { bảo) } \\
\text { + Chương trình nới lỏng định } \\
\text { lượng không giới hạn }\end{array}$ \\
\hline
\end{tabular}

Nguồn: Báo cáo nghiên cứu của Đại học kinh tế Quốc dân (Dân\&, 2020)

COVID-19 tác động mạnh mẽ lên nền tảng phát triển doanh nghiệp, phát triển kinh tế, thúc đẩy tư duy mới trong các cơ quan nhà nước và chủ điều hành.

Đại dịch covid 19 đã gây ra khủng hoảng toàn cầu, tác động lên nhiều ngành nghề khác nhau cũng như đời sống tinh thần của con người. "Bình thường mới" đề cập tới sự thay đổi trong các hoạt động, các mối quan hệ xã hội và hành vi của con người sau đại dịch. Trạng thái "bình thường mới” là những điều thay đổi so với cái cũ, cụ thể đối với doanh nghiệp là trạng thái mà tại đó con người vừa đảm bảo tập trung chống dịch hiệu quả, vừa khôi phục và phát triển lại nền kinh tế như lúc ban đầu. Dịch bệnh là vấn đề cấp thiết, nan giải trên toàn thế giới, tác động đến mọi giai tầng xã hội không phân biệt trình độ phát triển hay thể chế chính trị. Tác động nặng nề của dịch bệnh đòi hỏi con người phải có khả năng chống chịu và thích nghi với bối cảnh mới.Giãn cách xã hội đã ảnh hưởng nghiêm trọng đến lượng cung hàng hóa của doanh nghiệp, gây đứt gãy chuỗi cung ứng, mất nguồn vốn đầu tư trực tiếp của các đối tác nước ngoài.

Trên cơ sở chính sách đã ban hành năm 2020, Bộ Tài chính đã đánh giá tình hình thực hiện, những vướng mắc khó khăn, những kết quả đã đạt được để tiếp tục có chính sách kéo dài trong năm 2021. Ngày 19/4, Chính phủ đã ban hành Nghị định số 52/2021/NĐ-CP để tiếp tục gia hạn, giãn giảm đối với các loại thuế cũng như tiền thuê đất năm 2021. Thời hạn gia hạn là 31/12/2021. Nghị định này đã bổ sung thêm một số đối tượng bị ảnh hưởng trực tiếp bởi dịch Covid-19, ví dụ như: phát thanh, truyền hình, các lĩnh vực về sửa chữa máy móc, thiết bị, thoát nước... Các đối tượng khác cũng đã được bổ sung thêm trong nghị định này (Nguyễn Minh Phong, 2021).

Ngày 1/7/2021, Chính phủ ban hành Nghị quyết 68 "Về một số chính sách hỗ trợ người lao động và người sử dụng lao động gặp khó khăn do đại dịch COVID-19”. Nghị quyết này có một số điểm như sau:

- Giảm mức đóng bảo hiểm tai nạn lao động, bệnh nghề nghiệp:

- Tạm dừng đóng quỹ hưu trí và tử tuất 
- Hỗ trợ đào tạo, duy trì việc làm cho người lao động

- Hỗ trợ người lao động tạm hoãn hợp đồng lao động, nghỉ việc không hường lương

- Hỗ trợ người lao động ngừng việc

- Hỗ trợ người lao động chấm dứt hợp đồng lao động

- Hỗ trợ tiền ăn với người điều trị nhiễm COVID-19

- Hỗ trợ nghệ sĩ, nghệ thuật

- Hỗ trợ hộ kinh doanh

- Chính sách cho vay trả lương ngừng việc, trả lương phục hồi sản xuất

- Hỗ trợ đối với người lao động có giao kết hợp đồng và một số đối tượng đặc thù khác.

Tính đến ngày 23/9/2021, sau gần 3 tháng thực hiện NQ 68, theo báo cáo của 63 tỉnh thành tổng kinh phí thực hiện trên 14,2 nghìn tỷ đồng, hỗ trợ cho trên 17,7 triệu đối tượng (trong đó gồm 379.340 đơn vị sử dụng lao động, trên 17,4 triệu người lao động và các đối tượng khác). Bên cạnh kết quả đạt được, quá trình đánh giá tình hình triển khai thực hiện Nghị quyết số 68/NQ-CP thực tế tại các địa phương và tổng hợp kiến nghị, đề xuất của các đối tượng hưởng chính sách cho thấy tiến độ thực hiện các chính sách còn khá chậm, kết quả thực hiện tại một số chính sách chưa cao (Hồng Kiều, 2021).

Ngày 8/10/2021, Phó Thủ tướng Chính phủ Lê Minh Khái đã ký ban hành Nghị quyết số 126/NQ-CP sửa đổi, bổ sung Nghị quyết số 68/NQ-CP ngày 1/7/2021 của Chính phủ về một số chính sách hỗ trợ NLĐ, người SDLĐ gặp khó khăn do đại dịch Covid-19. Theo đó, Nghị quyết có bổ sung một số quy định về: đơn giản thủ tục hỗ trợ chính sách BHXH; Quy định rõ chính sách hỗ trợ NLĐ; Bỏ điều kiện nợ xấu đối với DN vay trả lương ngừng việc; Bổ sung đối tượng người cao tuổi, người khuyết tật.

Trong tháng 9/2021, để đối phó với tình hình đợt dịch bệnh thứ 4 căng thẳng, Chính phủ tiếp tục ban hành 2 Nghị quyết quan trọng để hỗ trợ doanh nghiệp và người lao động gặp khó khăn đó là: Nghị quyết số 105/NQ-CP về hỗ trợ doanh nghiệp, hợp tác xã, hộ kinh doanh trong bối cảnh dịch COVID-19 và Nghị quyết số $116 / \mathrm{NQ}-\mathrm{CP}$ về hỗ trợ người lao động, người sử dụng lao động bị ảnh hưởng bởi đại dịch COVID-19 từ Quỹ bảo hiểm thất nghiệp. Không chỉ có những chính sách mới dành cho doanh nghiệp, Nghị quyết số 116/NQ-CP về hỗ trợ người lao động, người sử dụng lao động bị ảnh hưởng bởi đại dịch COVID-19 từ Quỹ bảo hiểm thất nghiệp của Chính phủ cũng là một chính sách mang lại niềm động viên rất lớn đến người lao động.

Ngày 11/10.2021, Chính phủ đã ra Nghị quyết số 128/NQ-CP: Ban hành quy định tạm thời "Thích ứng an toàn, linh hoạt, kiểm soát hiệu quả dịch COVID -10". Theo nghị quyết này, mọi hoạt động của xã hội đều căn cứ theo cấp độ dịch quy mô từ cấp xã được quy định:

- Cấp 1: Nguy cơ thấp (bình thường mới) tương ứng với màu xanh.

- Cấp 2: Nguy cơ trung bình tương ứng với màu vàng.

- Cấp 3: Nguy cơ cao tương ứng với màu cam.

- Cấp 4: Nguy cơ rất cao tương ứng với màu đỏ. 
Một số "bước ngoặt” khác trong Nghị quyết số 128/NQ-CP: tạm thời không áp dụng Chỉ thị 15, 16 \& 19; Quy định về hoạt động đi lại, sản xuất... ở từng vùng nguy cơ. Sau khi xác định được cấp độ dịch các địa phương sẽ áp dụng các biện pháp phòng chống tương ứng để đảm bảo phòng chống dịch hiệu quả. Địa phương được áp dụng linh hoạt. Đảm bảo không trái với quy định của trung ương, không gây ách tắc lưu thông hàng hóa, sản xuất kinh doanh và đi lại, sinh hoạt của nhân dân.

Thủ tướng, Chính phủ và các bộ, ban, ngành đã ban hành nhiều chủ trương, chính sách, giải pháp nhằm kịp thời ứng phó với Covid 19 để tháo gỡ khó khăn, khôi phục lại đà sản xuất, phục hồi lại nền kinh tế sau thời gian bị đình trệ do ảnh hưởng của dịch bệnh. Nhìn chung những chính sách được đưa ra đều có sự kết hợp giữa chính sách tài khóa, chính sách tiền tệ và các chính sách hỗ trợ an sinh xã hội, cơ bản phù hợp với diễn biến và tác động của dịch bệnh, tương đồng với cách tiếp cận mới của nhiều quốc gia trên thế giới, được người dân và doanh nghiệp đánh giá cao. Các chính sách đưa ra đều được thực hiện với chi phí thấp, phù hợp với tình hình thực tiễn và không gây ảnh hưởng đến sự cân đối giữa các nền kinh tế, hơn thế nữa còn có thể bảo lưu cho việc thực hiện các giải pháp sắp tới. Bên cạnh tính hiệu quả của chính sách, giải pháp vẫn còn tồn đọng những vướng mắc trong quá trình thực thi. Một số chính sách được thực thi mang lại hiệu quả chưa cao. Giai đoạn đầu còn thiếu linh hoạt, thủ tục rườm rà dẫn đến việc các doanh nghiệp không thể tiếp cận thông tin kịp thời, khó tiếp cận, nhất là đối với doanh nghiệp vừa, nhỏ và siêu nhỏ.Nhiều chính sách được ban hành vẫn mang tính ứng phó tạm thời, trước mắt,chưa có chính sách tập trung cho từng ngành, lĩnh vực có tính chất dài hạn theo hướng phục hồi hơn là giải cứu ngắn hạn.

Nghị quyết số 128 được ban hành rất kịp thời, phù hợp, như một cánh cửa mở ra cho doanh nghiệp, tạo cơ hội việc làm trở lại cho người dân, tạo đà sản xuất, cung ứng sản phẩm và từng bước giúp Việt Nam khôi phục lại nền kinh tế. Đây là Nghị quyết được người dân, doanh nghiệp, các tầng lớp xã hội mong đợi, đồng tình, đánh giá cao và cho rằng Nghị quyết đã tạo ra bước ngoặt trong tư duy, cách thức mới trong phòng chống dịch. Chính sách chống dịch sẽ quy về một mối, thống nhất trong toàn quốc, góp phần bảo vệ tối đa sức khỏe, tính mạng của người dân; khôi phục và phát triển kinh tế - xã hội; thực hiện mục tiêu kép, đưa cả nước chuyển sang bình thường mới.

Tình hình dịch bệnh COVID-19 diễn biến phức tạp khiến hoạt động sản xuất Công ty TNHH Bao bì Phúc Thịnh bị trì trệ. Đặc biệt, trong cao điểm giãn cách, doanh thu giảm khoảng $70 \%$. Trong khi đó, mỗi tháng công ty này phải chi ra hơn 700 triệu đồng, gồm tiền lương, bảo hiểm xã hội, điện nước, lãi vay... khoản tương đối nặng là thuê mặt bằng 150 triệu đồng cũng là gánh nặng lớn đối với công ty. Vì vậy, nhờ có các chính sách của Chính phủ $\mathrm{DN}$ được gia hạn, miễn giảm tiền thuế thu nhập $\mathrm{DN}$, tiền thuê đất trong kỳ quyết toán thuế rất quan trọng và có ý nghĩa với $\mathrm{DN}$, giúp $\mathrm{DN}$ có nguồn lực tài chính chi trả các chi phí sản xuất, đặc biệt là chi trả đều đặn tiền lương cho lao động cũng như các chính sách hỗ trợ người lao động gặp khó khăn trong đợt dịch vừa qua.

Về du lịch, Công ty du lịch Vinpearl, với 45 cơ sở khách sạn, resort, khu vui chơi giải trí, sân golf... trên toàn quốc, áp dụng các quy trình nghiêm ngặt để sẵn sàng đón khách. Đại diện Vinpearl cho hay $100 \%$ nhân viên trực tiếp phục vụ du khách đang hoàn thành việc tiêm vaccine 2 mũi theo lộ trình trên toàn quốc. Bên cạnh tuân thủ hướng dẫn trong kế hoạch triển 
khai đón khách của các địa phương và Bộ Văn hóa Thể thao và Du lịch, Vinpearl còn đưa ra bộ tiêu chuẩn an toàn nâng cao. Về phía công ty lữ hành, Vietravel đã mở lại hơn 30 văn phòng, sau hơn 4 tháng. Trong tháng 10, công ty tập trung vào nhóm sản phẩm tại TP HCM đến các vùng xanh như tour Cần Giờ (1-2 ngày), staycation, Vũng Tàu, Tây Ninh, tour đón người Việt về nước hay các chuyên gia đến Việt Nam làm việc... Tiếp đến trong tháng 11 công ty sẽ mở rộng ra sản phẩm liên vùng, với các sản phẩm đường bộ từ TP HCM đến Phan Thiết, Nha Trang, Đà Lạt và miền Tây. (Lan Hương, 2021)

Về sản xuất, tính đến ngày 28/10, tại TP. Hồ Chí Minh, hơn 1.300 công ty, nhà máy trong các khu chế xuất khu công nghiệp $(\mathrm{KCX}-\mathrm{KCN})$ đã mở cửa trở lại, đạt trên $92 \%$. Đặc biệt, tại Khu công nghệ cao TP. Hồ Chí Minh, 100\% DN đã hoạt động trở lại. Đã có 1.968 DN trong các $\mathrm{KCN}$ trên địa bàn tỉnh Bình Dương tiến hành khôi phục lại hoạt động sản xuất kinh doanh, đạt trên $96 \%$. Tương tự, tại Đồng Nai, trên 92\% DN trong các KCN của tỉnh đã khôi phục sản xuất, trong đó có nhiều nhà máy hoạt động hết công suất. (Thu Dịu, 2021)

Nhờ có các chính sách phù hợp và kịp thời hỗ trợ các doanh nghiệp, năm 2021 mặc dù là năm Việt Nam chịu tác động lớn bởi dịch bệnh COVID -19 mà nền kinh tế của nước ta vẫn rất khả quan. Theo đó, tổng sản phẩm trong nước (GDP) quý IV/2021 ước tính tăng 5,22\% so với cùng kỳ năm trước, tuy cao hơn tốc độ tăng 4,61\% của năm 2020 nhưng thấp hơn tốc độ tăng của quý IV các năm 2011-2019. Tính chung năm 2021, GDP năm 2021 tăng 2,58\% (quý I tăng 4,72\%; quý II tăng 6,73\%; quý III giảm 6,02\%; quý IV tăng 5,22\%) so với năm trước do dịch Covid-19 ảnh hưởng nghiêm trọng tới mọi lĩnh vực của nền kinh tế, đặc biệt là trong quý III/2021 nhiều địa phương kinh tế trọng điểm phải thực hiện giãn cách xã hội kéo dài để phòng chống dịch bệnh (BBT, 2021a).

Một số chỉ tiêu kinh tế - xã hội chủ yếu năm 2021 như sau:

- Tổng sản phẩm trong nước (GDP) tăng 2,58\%

- Chỉ số sản xuất công nghiệp (IIP) tăng 4,8\%

- Số doanh nghiệp thành lập mới: 116.837 doanh nghiệp

- Vốn đầu tư toàn xã hội thực hiện tăng 3,2\%

- Chỉ số giá tiêu dùng bình quân tăng 1,84\%

- Lạm phát cơ bản tăng $0,81 \%$

- Tổng mức bán lẻ hàng hóa và doanh thu dịch vụ tiêu dùng giảm 3,8\%

- Tổng kim ngạch xuất khẩu hàng hóa tăng 19\%

- Tổng kim ngạch nhập khẩu hàng hóa tăng 26,5\%

- Xuất siêu: 4 tỷ USD

- Khách quốc tế đến Việt Nam giảm 95,9\%

- Lực lượng lao động từ 15 tuổi trở lên: 50,5 triệu người

- Lao động từ 15 tuổi trở lên đang làm việc: 49 triệu người 
- Tỷ lệ thất nghiệp của lực lượng lao động trong độ tuổi: 3,22\%

- Tỷ lệ thiếu việc làm của lực lượng lao động trong độ tuổi: 3,10\%

Năm 2021, sự bùng phát mạnh của làn sóng Covid-19 lần thứ tư cùng với các đợt phong tỏa nghiêm ngặt, giãn cách kéo dài (đặc biệt là quý III/2021) đã tác động tiêu cực đến gia tăng số lượng doanh nghiệp. Tổng số doanh nghiệp gia nhập và tái gia nhập thị trường trong năm 2021 đạt gần 160 nghìn doanh nghiệp, giảm 10,7\% so với năm 2020; 119,8 nghìn doanh nghiệp rút lui khỏi thị trường, tăng $17,8 \%$, trong đó phần lớn là các doanh nghiệp thành lập dưới 5 năm, quy mô vốn nhỏ. (BBT, 2021c)

Việc ban hành và triển khai kịp thời Nghị quyết số 128/NQ-CP ngày 11/10/2021 đã góp phần quan trọng trong khôi phục sản xuất và thúc đẩy thị trường, từng bước tạo niềm tin cho các doanh nghiệp. Kết quả điều tra xu hướng kinh doanh của các doanh nghiệp ngành công nghiệp chế biến, chế tạo cho thấy doanh nghiệp lạc quan về tình hình sản xuất kinh doanh trong quý I/2022 với 81,7\% doanh nghiệp đánh giá sẽ ổn định và tốt hơn so với quý IV/2021. (BBT, 2021c)

Quý IV/2021, số doanh nghiệp đăng ký thành lập mới đạt 31,4 nghìn doanh nghiệp với số vốn đăng ký 415,3 nghìn tỷ đồng và số lao động đăng ký là 205,1 nghìn lao động, tăng $70,4 \%$ về số doanh nghiệp, tăng $64,1 \%$ về số vốn đăng ký và tăng $24,7 \%$ về số lao động so với quý III/2021. Như vậy chỉ sau hơn hai tháng thực hiện Nghị quyết số 128/NQ-CP, tình hình đăng ký kinh doanh của doanh nghiệp trong những tháng cuối năm 2021 đã khởi sắc rõ nét. (Cục Quản lý đăng ký kinh doanh, 2021).

Tính chung năm 2021, cả nước có 116,8 nghìn doanh nghiệp đăng ký thành lập mới với tổng số vốn đăng ký là 1.611,1 nghìn tỷ đồng và tổng số lao động đăng ký gần 854 nghìn lao động, giảm $13,4 \%$ về số doanh nghiệp, giảm $27,9 \%$ về vốn đăng ký và giảm $18,1 \%$ về số lao động so với năm trước. Vốn đăng ký bình quân một doanh nghiệp thành lập mới trong năm 2021 đạt 13,8 tỷ đồng, giảm 16,8\% so với năm trước. Nếu tính cả 2.524,9 nghìn tỷ đồng vốn đăng ký tăng thêm của 43,5 nghìn doanh nghiệp tăng vốn, tổng số vốn đăng ký bổ sung vào nền kinh tế trong năm nay là 4.136 nghìn tỷ đồng, giảm $25,8 \%$ so với năm trước. Bên cạnh đó, còn có 43,1 nghìn doanh nghiệp quay trở lại hoạt động (giảm 2,2\% so với năm 2020), nâng tổng số doanh nghiệp thành lập mới và doanh nghiệp quay trở lại hoạt động năm 2021 lên gần 160 nghìn doanh nghiệp, giảm 10,7\% so với năm trước. Bình quân một tháng có 13,3 nghìn doanh nghiệp thành lập mới và quay trở lại hoạt động. (Cục Quản lý đăng ký kinh doanh, 2021).

Kết quả điều tra xu hướng kinh doanh của các doanh nghiệp ngành công nghiệp chế biến, chế tạo trong quý IV/2021 cho thấy: Có 44\% số doanh nghiệp đánh giá tình hình sản xuất kinh doanh tốt hơn so với quý III/2021; 31,1\% số doanh nghiệp cho rằng tình hình sản xuất kinh doanh ổn định và $24,9 \%$ số doanh nghiệp đánh giá gặp khó khăn[5]. Dự kiến quý I/2022, có 45,6\% số doanh nghiệp đánh giá xu hướng sẽ tốt lên so với quý IV/2021; 36,1\% số doanh nghiệp cho rằng tình hình sản xuất kinh doanh sẽ ổn định và $18,3 \%$ số doanh nghiệp dự báo khó khăn hơn. (BBT, 2021b)

Trong bối cảnh dịch Covid-19 tiếp tục diễn biến phức tạp, kinh tế - xã hội nước ta vẫn duy trì tăng trưởng và đạt được kết quả tích cực trên các lĩnh vực là do sự vào cuộc của cả hệ 
thống chính trị, sự chỉ đạo, điều hành kịp thời, quyết liệt, sát sao của Chính phủ, Thủ tướng Chính phủ cùng với sự nỗ lực thực hiện của các cấp, các ngành, địa phương, cộng đồng doanh nghiệp và nhân dân cả nước. Các cơ quan ở Trung ương và địa phương đã thực hiện tốt và hiệu quả công tác phòng, chống dịch; nhanh chóng triển khai Quỹ vắc-xin phòng chống Covid-19 để tiếp nhận, quản lý, sử dụng các nguồn viện trợ, hỗ trợ mua và tự nghiên cứu, sản xuất vắcxin, tiêm phòng miễn phí cho người dân nhằm đạt mục tiêu kinh tế - xã hội năm 2021 cao nhất có thể. Nền kinh tế vẫn giữ được mức tăng trưởng, tuy không đạt được mục tiêu đề ra nhưng an sinh xã hội được đảm bảo, kinh tế vĩ mô ổn định, lạm phát được kiểm soát ở mức thấp.

Tóm lại, việc phục hồi kinh tế, an sinh xã hội trong bối cảnh dịch COVID-19 phải có mục tiêu, lộ trình cụ thể, và Việt Nam đang rất cần một chính sách kịp thời, phù hợp để có thể hồi sinh doanh nghiệp trong thời kì covid. "Trạng thái bình thường mới” góp phần phát triển kinh tế - xã hội, nâng cao khả năng thích ứng của mọi lĩnh vực trong đời sống xã hội của đất nước trong bối cảnh mới, nhất là bối cảnh đại dịch COVID -19. Trạng thái này đòi hỏi mọi cá nhân, cộng đồng, tổ chức và giai tầng xã hội, nhất là đội ngũ cán bộ lãnh đạo, quản lý phải có tư duy mới, tầm nhìn mới, cách làm mới để đạt được những mục tiêu mà Nghị quyết Đại hội XIII của Đảng đã đề ra.

Tuy nhiên, tình hình dịch bệnh Covid-19 vẫn còn tiếp tục diễn biến khó lường, nguy cơ dịch bệnh có thể bùng phát trở lại và xảy ra ở bất cứ đâu, bất cứ khi nào. Dịch bệnh cũng đã làm thay đổi nhiều mặt của đời sống kinh tế - xã hội, thói quen tiêu dùng của người dân, từ đó gây ra nhiều khó khăn, thách thức cho các doanh nghiệp trong việc dự báo thị trường để ước tính kết quả kinh doanh. Những nguy cơ đứt gãy chuỗi cung ứng cũng như nguồn cung lao động có thể trở lại với doanh nghiệp nếu Nhà nước không có các biện pháp kịp thời để tiếp tục kiểm soát hiệu quả dịch bệnh, đặc biệt là tại các tỉnh, thành phố phía Nam.

Do vậy, các cấp, các ngành, các Hiệp hội ngành hàng cần tiếp tục vào cuộc nhằm tháo gỡ khó khăn cho doanh nghiệp, nối lại nhanh chuỗi sản xuất, khôi phục nền kinh tế, theo tinh thần Nghị quyết số $128 / \mathrm{NQ}-\mathrm{CP}$ ngày $11 / 10 / 2021$ của Chính phủ và các quy định, hướng dẫn tạm thời về thích ứng an toàn, linh hoạt, kiểm soát hiệu quả dịch Covid-19. Bên cạnh đó, Nhà nước cần sớm ban hành chính sách áp dụng linh hoạt quy định về giờ làm thêm trong thời kỳ dịch bệnh, cho phép người lao động có thể làm thêm nhiều giờ hơn quy định (không quá 400 giờ/năm) để tạo điều kiện cho các doanh nghiệp tăng ca sản xuất, bảo đảm tiến độ giao hàng.

"Trạng thái bình thường mới" đã, đang và sẽ tạo ra cả cơ hội và thách thức đan xen, đòi hỏi Đảng, Nhà nước, hệ thống chính trị, hệ thống kinh tế, hệ thống xã hội phải có những cách tiếp cận mới, những cách thức và biện pháp mới hoạch định, chỉ đạo, điều hành và thực hiện chính sách phát triển kinh tế - xã hội mang tính hệ thống, đồng bộ.

Về dài hạn, dưới lăng kính của hệ xử lý thông tin 3D (Vuong, Q.H., 2022) và khung văn hóa, các chính sách của nhà nước cần tập trung đẩy mạnh đầu tư cho khoa học công nghệ (Vuong, 2018), truyền thông thông tin, hợp tác với các chuyên gia, nâng cao nhận thức thực hành kỷ luật chống dịch của người dân. Đây không chỉ là điều kiện để tìm ra các giải pháp sáng tạo mà còn xây dựng chuyển đổi văn hóa chống dịch một cách bền vững.

\section{TÀI LIỆU THAM KHẢO}

BBT. (2021a). TÁC ĐỘNG CỦA DICH COVID-19 ĐẾN TĂNG TRƯỞNG CÁC KHU VỬC 
KINH TÉ QUÝ III NĂM 2021. Tổng Cục Thống Kê.

BBT. (2021b). Thông cáo báo chí - Doanh nghiệp. Tổng Cục Thống Kê.

BBT. (2021c). THÔNG CÁO BÁO CHÍ VỀ TİNH HÌNH KINH TẾ-XÃ HỘ QUÝ IV VÀ NĂM 2021. Tổng Cục Thống Kê.

Cục Quản lý đăng ký kinh doanh, B. K. hoạch và Đ. tư. (2021). Hệ thống thông tin đăng ký doanh nghiệp quốc gia.

Dân\&, N. nghiên cứu thành viên Đ. học K. tế Q. dân\& các chuyên gia T. chức J. (2020). Úng Phó Với Covid-19 Và Các Khuyến Nghị. 27, 8-26.

Đỗ Văn Quân. (2021). Thích ứng với “trạng thái bình thường mới” trong phòng, chống dịch COVID-19. Tạp Chí Ban Tuyên Giáo Trung Uơng.

Hồng Kiều. (2021). Hỗ trợ người dân gặp khó khăn trong COVID-19: Chính sách mới trong trạng thái bình thuoơng mới. Xây Dựng Đảng.

La, V. P. et al. (2020). Policy response, social media and science journalism for the sustainability of the public health system amid the COVID-19 outbreak: The vietnam lessons. Sustainability (Switzerland), 12(7). https://doi.org/10.3390/su12072931

Lan Hương, H. N. (2021). Một tháng hồi sinh của du lịch Việt Nam. VNExpress.

Nguyễn Minh Phong. (2021). Để hô̂ trợ doanh nghiệp vuợt qua đại dịch COVID-19. Báo Điện Tử Chính Phủ.

Phúc Minh. (2010). WEF: Đi tìm "trạng thái bình thường mới" của kinh tế toàn cầu. Kinh Tế Sài Gòn Online.

Thu Dịu. (2021). Các chính sách hỗ trợ về thuế tù̀ng buớc vực dậy doanh nghiệp sau dịch. Tạp Chí Tài Chính.

Vuong, Q.H., et al. (2022). Covid-19 vaccines production and societal immunization under the serendipity-mindsponge-3D knowledge management theory and conceptual framework. Humanities \& Social Sciences Communications, 9, 22. https://www.nature.com/articles/s41599-022-01034-6

Vuong, Q. H. (2018). The (ir)rational consideration of the cost of science in transition economies. Nature Human Behaviour, 2(1), 5. https://doi.org/10.1038/s41562-0170281-4 